\section{SAT0573 SOCIODEMOGRAPHIC, CLINICAL CHARACTERISTICS AND JOINT INVOLVEMENT OF A CHIKUNGUNYA EPIDEMIC IN COLOMBIA}

J.C. Rueda ${ }^{1}$, J.-I. Angarita ${ }^{1}$, A.M. Santos ${ }^{1}$, E.-L. Saldarriaga ${ }^{1}$, I. Pelaez-Ballestas ${ }^{2}$, E. Couto-Luvie ${ }^{1}$, J. Londono ${ }^{3} \cdot{ }^{1}$ Reumatología, Universidad de la Sabana, Chia, Colombia; ${ }^{2}$ Reumatología, Hospital General de México, México, Mexico; ${ }^{3}$ Reumatología, Universidad de la Sabana-Hospital Militar Central, Bogotá, Colombia

Background: During 2014 and 2015 a chikungunya epidemic took place in Colombia concurrently with a COPCORD study across the country.

Objectives: To describe the clinical characteristics of CHIKV infection in 6 different cities in Colombia and determine the most frequently associated clinical picture with CHIKV.

Methods: World Health Organization criteria was used to identify CHIKV patients. A complete characterization and confirmation was established with CHIKV immunoglobulin $\mathrm{G}$ and $\mathrm{IgM}$ serology. Four possible scenarios were stablished: patients who met or not the criteria for probable case, and patients who met or not the criteria for confirmed case. $P$ values were calculated between patients who met or not met the criteria. Sensibility and specificity was calculated for the WHO criteria.

Results: A total of 604 patients with MSK symptoms were evaluated in 6 different cities. The sociodemographic, clinical characteristics and joint involvement of the studied population is depicted in tables 1 and 2 . Sensibility and specificity of the WHO criteria were $56.2 \%$ and $91.1 \%$ respectively (PPV: $83.3 \%$, NPV: $74.4 \%$ ).

Table 1. Sociodemographic and Clinical Characteristics of Patients with Positive COPCORD

\begin{tabular}{|c|c|c|c|c|}
\hline & \multicolumn{2}{|c|}{ WHO Probable Case Criteria } & \multicolumn{2}{|c|}{ WHO Confirmed Case Criteria } \\
\hline & $\begin{array}{l}\text { Met Criteria } \\
\quad(\mathrm{n}: 180)\end{array}$ & $\begin{array}{l}\text { Did Not Met Criteria } \\
\qquad(\mathrm{n}: 424)\end{array}$ & $\begin{array}{l}\text { Met Criteria } \\
(\mathrm{n}: 150)\end{array}$ & $\begin{array}{l}\text { Did Not Met Criteria } \\
\text { (n: 454) }\end{array}$ \\
\hline Age (mean; SD) in years & $46,1 \pm 16,2$ & $49,5 \pm 17,8$ & $44,9 \pm 16,3$ & $49,7 \pm 17,6^{*}$ \\
\hline Gender Female (\%) & $133(73,9)$ & $285(67,2)$ & $113(75,3)$ & $305(67,2)$ \\
\hline $\mathrm{CHIKV} \mathrm{IgG} \mathrm{in} \mathrm{SU}$ & $36.5+229^{*}$ & $162+183$ & $429+194^{*}$ & $154+180$ \\
\hline $\begin{array}{l}\text { CHIKV IgM in SU } \\
\text { (mean; SD) }\end{array}$ & $9,0 \pm 6,9^{\star}$ & $6,6 \pm 5,1$ & $9,8 \pm 7,2^{*}$ & $6,5 \pm 4,9$ \\
\hline Fever $(\%)$ & $180(100)^{*}$ & $0(0,0)$ & $150(100)^{\star}$ & $30(6,6)$ \\
\hline Rash (\%) & $126(70,0)^{*}$ & $28(6,6)$ & $109(72,7)^{*}$ & $45(9,9)$ \\
\hline
\end{tabular}

Table 2. Clinical Characteristics of Joint Involvement

$\frac{\text { Table 2. Clinical Characteristics of Joint Involvement }}{\text { WHO Probable Case Criteria }}$

\begin{tabular}{|c|c|c|c|c|}
\hline & \multicolumn{2}{|c|}{ WHO Probable Case Criteria } & \multicolumn{2}{|c|}{ WHO Contirmed Case Criteria } \\
\hline & $\begin{array}{l}\text { Met Criteria } \\
(\mathrm{n}: 180)\end{array}$ & $\begin{array}{c}\text { Did Not Met Criteria } \\
\text { (n: 424) }\end{array}$ & $\begin{array}{l}\text { Met Criteria } \\
\text { (n: 150) }\end{array}$ & $\begin{array}{l}\text { Did Not Met Criteria } \\
\text { (n: 454) }\end{array}$ \\
\hline \multicolumn{5}{|l|}{ Symmetry (\%) } \\
\hline Arthralgia & $177(98,3)^{\star}$ & $215(50,7)$ & $147(98,0)^{\star}$ & $245(54,0)$ \\
\hline Arthritis & $85(47,2)^{\star}$ & $14(3,3)$ & $80(53,3)^{\star}$ & $19(4,2)$ \\
\hline \multicolumn{5}{|l|}{ Arthralgia (\%) } \\
\hline Elbows & $58(32,2)^{\star}$ & $60(14,2)$ & $48(32,0)^{\star}$ & $70(15,4)$ \\
\hline Wrists & $78(43,3)^{\star}$ & $67(15,8)$ & $65(43,3)^{\star}$ & $80(17,6)$ \\
\hline Hands & $120(66,7)^{\star}$ & $126(29,7)$ & $103(68,7)^{\star}$ & $143(31,5)$ \\
\hline Knees & $128(71,1)^{\star}$ & $200(47,2)$ & $107(71,3)^{*}$ & $221(48,7)$ \\
\hline Ankles & $103(57,2)^{\star}$ & $95(22,5)$ & $92(61,3)^{\star}$ & $106(23,4)$ \\
\hline Feet & $71(39,4)^{\star}$ & $94(22,2)$ & $65(43,3)^{*}$ & $100(22,0)$ \\
\hline \multicolumn{5}{|l|}{ Arthritis (\%) } \\
\hline Wrists & $17(9,4)^{\star}$ & $4(0,9)$ & $16(10,7)^{\star}$ & $5(1,1)$ \\
\hline Hands & $44(24,4)^{\star}$ & $6(1,4)$ & $42(28,0)^{\star}$ & $8(1,8)$ \\
\hline Knees & $21(11,7)^{\star}$ & $4(0,9)$ & $20(13,3)^{\star}$ & $5(1,1)$ \\
\hline Ankles & $43(23,9)^{\star}$ & $8(1,9)$ & $42(28,0)^{\star}$ & $9(2,0)$ \\
\hline Feet & $40(22,2)^{\star}$ & $7(1,7)$ & $39(26,0)^{\star}$ & $8(1,8)$ \\
\hline Myalgia (\%) & $130(72,2)^{\star}$ & $35(8,3)$ & $106(70,7)^{\star}$ & $59(13,0)$ \\
\hline Fatigue (\%) & $165(91,7)^{\star}$ & $41(9,7)$ & $137(91,3)^{\star}$ & $69(15,2)$ \\
\hline
\end{tabular}

${ }^{*} p<0,005$

Conclusions: Our study shows a clear clinical picture of systemic symptoms, high titters of CHIKV immunoglobulins, and a defined joint involvement, which will help clinicians to identify and differentiate CHIKV infection from other viral infections and MSK diseases. Also, the sensibility of the WHO criteria applied to our cohort of patients demonstrates the need to improve clinical criteria without the use of laboratory tests.

Disclosure of Interest: None declared

DOI: 10.1136/annrheumdis-2017-eular.1879

\section{SAT0574 PERFORMANCE OF IMMUNOGLOBULIN M AND G (IGM AND IGG) ANTIBODIES AGAINST CHIKUNGUNYA VIRUS (CHIKV) BY ENZYME-LINKED IMMUNOSORBENT (ELISA) TECHNIQUE}

J.C. Rueda ${ }^{1}$, J.-I. Angarita ${ }^{1}$, A.M. Santos ${ }^{1}$, E.-L. Saldarriaga ${ }^{1}$

I. Pelaez-Ballestas ${ }^{2}$, P. López-Morales ${ }^{1}$, J. Londono ${ }^{3} .{ }^{1}$ Reumatología,

Universidad de la Sabana, Chia, Colombia; ${ }^{2}$ Reumatología, Hospital General de México, México, Mexico: ${ }^{3}$ Reumatología, Universidad de la Sabana-Hospital Militar Central, Bogotá, Colombia

Background: CHIKV is suspected based on epidemiological and clinical criteria, however confirmation of the disease is only achieved by laboratory tests.
Laboratory diagnosis is made by two approaches: the detection of viral RNA and identification of the specific immune response by serological methods. Serological tests are the most frequently used laboratory methods for the diagnosis of CHIKV. IgM is the first detected antibodies during 4 to 6 days after onset of symptoms followed by IgG. In Colombia, CHIKV's probable cases are not mandatory to be confirmed, so there is no standardization for laboratory confirmation tests

Objectives: To evaluate the performance of $\lg M$ and $\lg G$ antibodies against CHIKV in a cohort of patients with CHIKV

Methods: IgM and IgG antibodies against CHIKV were measured by ELISA (AbcamÒ ab177835 and ab177835 anti-chikungunya virus IgM and IgG human ELISA kit, Cambridge, UK) technique in 604 patients with CHIKV suspicion. A typical case of $\mathrm{CHIKV}$ with high sensitivity and specificity obtained from a previous study was used as gold standard for diagnosis of CHIKV. Since CHIKV epidemic of 2014-2015 was the first to be reported in our country (Colombia), no second measurements of IgG were needed to confirmed infection.

Results: Cut off point for IgG was 14,3 SU and for IgM was 11,2 SU. Mean values for IgG was $36,7 \mathrm{SU}( \pm 22,7)$ in patients with CHIKV and 8,6 SU $(\mathrm{SD} \pm 6,3)$ for $\operatorname{lgM}$. Statistical significance was obtained for both $\lg G$ and $\lg M(p<0,0001)$ when comparing patients with and without CHIKV. Receiver operating characteristic (ROC) curves showed and area under the curve (AUC) of 0,81 for IgG and 0,65 for lgM (figure 1).

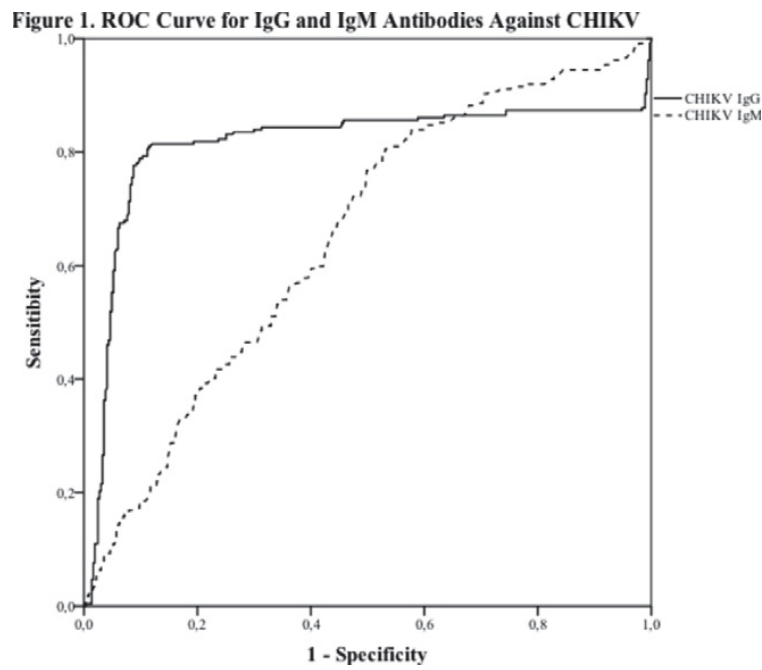

Conclusions: Our study revealed a good performance of $\lg G$ and regular performance of IgM for the diagnosis of CHIKV in a cohort of CHIKV patients from Colombia's epidemic. Cut off points for both IgG and IgM were measured for future reference.

Disclosure of Interest: None declared

DOI: 10.1136/annrheumdis-2017-eular.1886

\section{SAT0575 ASSOCIATION OF HUMAN LEUKOCYTE A, B AND DR ANTIGENS IN PATIENTS WITH CHIKUNGUNYA VIRUS INFECTION}

J.C. Rueda ${ }^{1}$, J.-I. Angarita ${ }^{1}$, A.M. Santos ${ }^{1}$, E.-L. Saldarriaga ${ }^{1}$,

I. Pelaez-Ballestas ${ }^{2}$, B. Zaldivar-Castaño ${ }^{1}$, J. Londono ${ }^{3} .{ }^{1}$ Reumatología,

Universidad de la Sabana, Chia, Colombia; ${ }^{2}$ Reumatología, Hospital General de México, México, Mexico; ${ }^{3}$ Reumatología, Universidad de la Sabana-Hospital Militar Central, Bogotá, Colombia

Background: Host factors like innate and adaptive immune response play an important part in disease susceptibility. Also, the role of host genetics factors in the pathogenesis of viral diseases have been reported. Human leukocyte antigen (HLA) is responsible for initiating innate and adaptive immune responses. Studies have demonstrated HLA class II alleles association to susceptibility or resistance to chikungunya virus infection (CHIKV), however there is no evidence of association studies of HLA class I and II in the Latin-American CHIKV epidemic. Objectives: To evaluate the association of human leukocyte $A, B$ and DR antigens in a group of Colombian patients with CHIKV.

Methods: Characterization of HLA allele A, B, and DR of 62 patients with confirmed CHIKV was compared with 100 unrelated healthy subjects as a control group. The comparison between the different allele frequencies in the patient group and the control population was performed using $\mathrm{chi}^{2}$, with Bonferroni correction. A $p$ value $<0.05$ was considered to be significant. The magnitude of associations was assessed using odds ratio $(\mathrm{OR})$ and confidence intervals $(\mathrm{Cl})$ of $95 \%$. To establish the homogeneity of the studied groups, the Hardy-Weinberg disequilibrium was used.

Results: Of the 62 patients studied 46 were female $(74,2 \%)$. The mean age was $45,0(\mathrm{SD} \pm 16,8)$ years. Most of the patients were from Barranquilla $(64,5 \%$; $\mathrm{n}: 40)$. Mean CHIKV immunoglobulin $\mathrm{G}(\mathrm{lgG})$ was $38,6 \mathrm{SU}(\mathrm{SD} \pm 21,7)$, while $\lg M$ was $13,3 \mathrm{SU}(\mathrm{SD} \pm 7,6)$. Also C reactive protein levels were high (mean: 14,7 
$\mathrm{mg} / \mathrm{L} ; \mathrm{SD} \pm 8,4)$. Association alleles of HLA-A, and DR are depicted in table 1. No association was found with HLA-B alleles.

\begin{tabular}{|c|c|c|c|c|c|c|}
\hline & Patients & Control & Odds Ratio & $\mathrm{Cl}$ & $p$ & $\mathrm{Cp}$ \\
\hline \multicolumn{7}{|l|}{ Resistance } \\
\hline$A^{*} 28$ & 0 & 11 & 0,0 & $0,0-\mathrm{INF}$ & 0,002 & 0,040 \\
\hline$A^{*} 29$ & 6 & 24 & 0,2 & $0,0-0,6$ & 0,002 & 0,048 \\
\hline \multicolumn{7}{|l|}{ Susceptibility } \\
\hline$A^{*} 68$ & 14 & 2 & 9,9 & $2,1-45,1$ & 0,000 & 0,008 \\
\hline$D R B 1{ }^{*} 01$ & 21 & 5 & 6,4 & $2,3-17,9$ & 0,000 & 0,001 \\
\hline$D R B 1{ }^{*} 04$ & 26 & 11 & 3,6 & $1,6-8,0$ & 0,000 & 0,010 \\
\hline$D R B 1 * 13$ & 24 & 8 & 4,6 & $1,9-11,1$ & 0,000 & 0,004 \\
\hline
\end{tabular}

CHIKV: chikungunya virus infection; $\mathrm{Cl}$ : confidence interval 95\%; $\mathrm{C} p$ : Bonferroni corrected $p$ value.

Conclusions: Our study demonstrated the alleles $A * 28$ and $A * 29$ to be associated with resistance to CHIKV, and alleles $A^{*} 68, D R B 1^{*} 01, D R B 1^{*} 04$ and $D R B 1^{*} 13$ to be associated with susceptibility to CHIKV. No association was found in any HLA-B alleles.

Disclosure of Interest: None declared

DOI: 10.1136/annrheumdis-2017-eular.1887

\section{SAT0576 IMPROVED CLINICAL SCENARIO FOR CHIKUNGUNYA DIAGNOSIS}

J.C. Rueda $^{1}$, J.-I. Angarita ${ }^{1}$, A.M. Santos ${ }^{1}$, E.-L. Saldarriaga ${ }^{1}$,

I. Pelaez-Ballestas ${ }^{2}$, M.J. Soares-Santeugini ${ }^{1}$, J. Londono ${ }^{3}$. ${ }^{1}$ Reumatología, Universidad de la Sabana, Chia, Colombia; ${ }^{2}$ Reumatología, Hospital General de México, México, Mexico; ${ }^{3}$ Reumatología, Universidad de la Sabana-Hospital Militar Central, Bogotá, Colombia

Background: The World Health Organization (WHO) criteria for chikungunya virus infection (CHIKV) have a specificity of $91,1 \%$ with a low sensibility of $56,2 \%$, which decreases the ability to detect patients with the infection. Because of this issue a group of rheumatology, epidemiology and bacteriology experts in diagnosing and treating CHIKV patients performed an agreement consensus on the clinical characteristics of CHIKV infection and proposed a set of clinical criteria. In order to test the performance of the new criteria and improve sensibility and specificity a clinical scenario was developed with the agreements from the expert panel and the clinical characteristics with higher odds ratios.

Objectives: To improve sensibility and specificity of a set of clinical criteria for the diagnosis CHIKV.

Methods: Odds ratios of the clinical features of patients with $\mathrm{CHIKV}$ infection were analysed. A clinical scenario was developed and sensitivity and specificity was calculated.

Results: 37 clinical characteristics were evaluated in a cohort of 604 patients with suspicion of $\mathrm{CHIKV}$. From those, 29 exhibited statistical significance and only 10 had high odds ratios (table 1). A clinical scenario with the following joint involvement (symmetrical arthritis of shoulders or wrists or hands or knees or ankles or feet) or systemic symptoms (fever or rash or myalgia or fatigue) poised a sensitivity of $74,2 \%$ (PPV: $83,5 \%$ ) and a specificity of $88,4 \%$ (NPV: $81,2 \%$ ). The following clinical characteristics extracted from the agreements of the consensus group were added to the clinical picture: origin from an epidemic area and abrupt onset of symptoms.

Table 1. Clinical Characteristics with High Odds Ratios

\begin{tabular}{lccccc}
\hline & \multicolumn{2}{c}{ WHO Confirmed Case Criteria } & Odds Ratio & $\mathrm{Cl}(95 \%)$ & $p$ \\
\cline { 2 - 3 } & $\begin{array}{c}\text { Met Criteria } \\
\text { (n: 150) }\end{array}$ & $\begin{array}{c}\text { Did Not Met Criteria } \\
\text { (n: 454) }\end{array}$ & & & \\
\hline $\begin{array}{c}\text { Symmetry (\%) } \\
\quad \text { Arthritis }\end{array}$ & $80(53,3)$ & $19(4,2)$ & 24,8 & $11,2-54,6$ & $<0,0001$ \\
$\begin{array}{c}\text { Arthritis (\%) } \\
\text { Wrists }\end{array}$ & $16(10,7)$ & $5(1,1)$ & 22,2 & $3,6-204,1$ & $<0,0001$ \\
Hands & $42(28,0)$ & $8(1,8)$ & 36,7 & $8,8-152,6$ & $<0,0001$ \\
Knees & $20(13,3)$ & $5(1,1)$ & 10,0 & $2,8-33,8$ & $<0,0001$ \\
Ankles & $42(28,0)$ & $9(2,0)$ & 24,4 & $7,5-79,3$ & $<0,0001$ \\
Feet & $39(26,0)$ & $8(1,8)$ & 69,3 & $9,6-510,8$ & $<0,0001$ \\
Myalgia (\%) & $106(70,7)$ & $59(13,0)$ & 13,0 & $8,1-20,7$ & $<0,0001$ \\
Fatigue (\%) & $137(91,3)$ & $69(15,2)$ & 16,9 & $10,9-26,8$ & $<0,0001$ \\
Fever (\%) & $150(100)$ & $30(6,6)$ & 13,1 & $8,4-20,5$ & $<0,0001$ \\
Rash (\%) & $109(72,7)$ & $45(9,9)$ & 14,0 & $8,5-22,9$ & $<0,0001$ \\
\hline
\end{tabular}

WHO: World Health Organization; Cl: Confidence Interval.

Conclusions: Our study demonstrated that the proposed clinical scenario for suspicion of CHIKV improves diagnostic sensibility with a slight decrease in specificity, increasing the chance of diagnosis without the need for laboratory tests. We propose that a patient from an epidemic area (fulfilling epidemiological criteria according to the WHO) with an abrupt onset of a clinical picture of symmetrical arthritis of any of the following joints: hands, wrists, shoulders, knees or feet, or the presence of any of the following systemic symptoms: fever, rash, fatigue or myalgia, is more likely to have CHIKV infection.

Disclosure of Interest: None declared

DOI: 10.1136/annrheumdis-2017-eular.1883

\section{SAT0577 MUSCULOSKELETAL MANIFESTATIONS OF TUBERCULOSIS: AN OBSERVATIONAL STUDY}

N. Gupta ${ }^{1}$, A. Bhatnagar ${ }^{2} .{ }^{1}$ Clinical Immunology \& Rheumatology, CHRistian Medical College, VELLORE; ${ }^{2}$ Pulmonology, Rajan Babu Tuberculosis Hospital, Delhi, India

Background: Data of musculoskeletal manifestations of tuberculosis is limited to case reports, series or retrospective study. To our knowledge there is no prospective study which has addressed this issue. So, we conducted this study to create awareness among the doctors about musculoskeletal manifestations of tuberculosis.

Objectives: To study the musculoskeletal manifestations of tuberculosis.

Methods: It was a prospective observational study which was conducted at a referral Tuberculosis Hospital in North India in the month of September \& October 2016. Patients from outpatient and inpatient department of pulmonology were recruited irrespective of the duration of anti tubercular therapy.

We included patients who had active tuberculosis as per World Health Organization (WHO) 2010 criteria. Patients with other chronic illnesses were excluded. A detailed history, examination and appropriate investigations (blood, urine, serological and radiological) of the 100 consecutive patients fulfilling the inclusion criteria was recorded

Results: Mean age of patients was $32.16 \pm 12.93$ years. Male to female ratio was 43:57. Mean duration of disease was $6.85 \pm 8.83$ months. Of the 100 patients, $60(60 \%)$ had pulmonary tuberculosis. Pleural tuberculosis presenting as pleural effusion was seen in $17(17 \%)$ patients. Abdominal tuberculosis was seen in 9 (9\%), tuberculous lymphadenopathy in $8(8 \%)$ and pott's spine in $4(7 \%)$. Eye tuberculosis and tubercular breast lump was seen in 1 patient each.

$83(83 \%)$ patients had first episode of tuberculosis while the other $17(17 \%)$ patients had second episode of tuberculosis. $74(74 \%)$ patients were on category 1 anti tuberculosis treatment (ATT), while $23(23 \%)$ were on category 2 ATT and $3(3 \%)$ were on modified ATT. Mean duration of ATT was $1.79 \pm 1.34$ months.

Fibromyalgia was classified in $21(21 \%)$ patients, polyarthralgia's were seen in 9 $(9 \%)$, pott's spine in $7(7 \%)$, osteomyelitis in $4(4 \%)$ and scleritis in $2(2 \%)$ patients. Uveitis, tenosynovitis, erythema induratum, subcutaneous abscess and dactylitis was seen in $1(1 \%)$ each. Rheumatological manifestations as septic arthritis, DILE, poncet's arthritis, tendinopathy, amyloidosis, gout, erythema nodosum and myositis were not seen in any patient.

In 21 patients who had fibromyalgia, 11 patients developed fibromyalgia with 2nd episode of tuberculosis amounting to $60.75 \%$ patients.

Conclusions: This is the first prospective study to look at the musculoskeletal manifestations of tuberculosis. Patients with active tuberculosis were found to have various rheumatological manifestations.

Acknowledgements: I acknowledge Dr Sushil Gupta, director of the Rajan Babu TB Hspital for allowing me to conduct this study

Disclosure of Interest: None declared

DOI: 10.1136/annrheumdis-2017-eular.1357

\section{SAT0578 LEFLUNOMIDE INHIBITS THE APOPTOSIS OF HUMAN EMBRYONIC LUNG FIBROBLASTS INFECTED BY HUMAN CYTOMEGALOVIRUS}

Q. Ren ${ }^{1}, \mathrm{H}$. Zeng ${ }^{2} .{ }^{1}$ Department of Pediatric Allergy, Immunology and Rheumatolog; ${ }^{2}$ Department of Pediatric Allergy, Immunology and Rheumatology, Guangzhou Women and Children's Medical Center, Guangzhou, China

Background: The immunomodulatory drug leflunomide (LEF) is frequently used for treating human cytomegalovirus (HCMV), but its antiviral mechanism is still unclear.

Objectives: In this study,we therefore investigated the effects of the active LEF metabolite A771726 on the HCMV lifecycle in human embryonic lung fibroblasts. We clarified the mechanism of LEF antiviral infection, and provide a new way to treat immune dysfunction patients with HCMV infection.

Methods: The experiment was divided into four groups:the control group, the HCMV group, the ganciclovir + HCMV group as well as the LEF + HCMV group. MTT was usedfor assessmentof the cell inhibitory rate. Apoptosis was measured by staining with fluoresceinisothiocyanate Annexin $\mathrm{V}$ and propidium iodide. Statistical significance was determined by paired $t$-test using SPSS software.

Results: The results of the study showed that cell proliferation was significantly inhibited by HCMV at 24 hours and 48 hours. With increasing HCMV concentration, the value-added inhibition of the cells was significantly decreased compared with the control group, and was statistically significant $(P<0.01)$. Ganciclovir can increase proliferation of cellsinfected with $\mathrm{HCMV}$;compared with the control group it was statistically significant $(P<0.05)$. Meanwhile,with LEF treatment cell proliferation was significantly improved at 24 hours and 48 hours, with statistical significance $(P<0.05)$. The apoptosis rate of human embryonic lung fibroblasts infected with HCMV increased significantly at 24 hours, 48 hours and 72 hours, and as time goes on the apoptosis rate increases statistically significantly $(P<0.01)$ compared with the control group The apoptosis rate of theHCMV infection group decreased by adding LEF, and was statistically significant $(P<0.05)$.

Conclusions: In this studywe show that LEF is an exciting new drug for cytomegalovirus infection. LEF significantly inhibited HCMV infection-induced apoptosis and proliferation, playing an important role in the treatment of patients infected by HCMV. In this study we explored the potential usefulness of LEF for 